\title{
THE GUTMAN INDEX AND THE EDGE-WIENER INDEX OF GRAPHS WITH GIVEN VERTEX-CONNECTIVITY
}

\author{
Jaya Percival Mazorodze \\ Department of Mathematics \\ University of Zimbabwe, Harare, Zimbabwe \\ e-mail: mazorodzejaya@gmail.com \\ Simon Mukwembi \\ Department of Mathematics \\ University of Zimbabwe, Harare, Zimbabwe \\ and \\ School of Mathematics, Statistics and Computer Science \\ University of KwaZulu-Natal \\ Durban, South Africa \\ e-mail: mukwembi@ukzn.ac.za \\ AND \\ TOMÁŠ VETRÍK ${ }^{1}$ \\ Department of Mathematics and Applied Mathematics \\ University of the Free State, Bloemfontein, South Africa \\ e-mail: vetrikt@ufs.ac.za
}

\begin{abstract}
The Gutman index and the edge-Wiener index have been extensively investigated particularly in the last decade. An important stream of research on graph indices is to bound indices in terms of the order and other parameters of given graph. In this paper we present asymptotically sharp upper bounds on the Gutman index and the edge-Wiener index for graphs of given order and vertex-connectivity $\kappa$, where $\kappa$ is a constant. Our results substantially generalize and extend known results in the area.
\end{abstract}

Keywords: Gutman index, edge-Wiener index, vertex-connectivity.

2010 Mathematics Subject Classification: 05C35, 05C12.

\footnotetext{
${ }^{1}$ The work of T. Vetrík has been supported by the National Research Foundation of South Africa; Grant numbers: 91499, 90793.
} 


\section{REFERENCES}

[1] M. Azari and A. Iranmanesh, Computation of the edge Wiener indices of the sum of graphs, Ars Combin. 100 (2011) 113-128.

[2] F. Buckley, Mean distance in line graphs, Congr. Numer. 32 (1981) 153-162.

[3] P. Dankelmann, I. Gutman, S. Mukwembi and H.C. Swart, The edge-Wiener index of a graph, Discrete Math. 309 (2009) 3452-3457. doi:10.1016/j.disc.2008.09.040

[4] A.A. Dobrynin and A.A. Kochetova, Degree distance of a graph: a degree analogue of the Wiener index, J. Chem. Inf. Comput. Sci. 34 (1994) 1082-1086. doi:10.1021/ci00021a008

[5] A.A. Dobrynin and L.S. Mel'nikov, Wiener index, line graphs and the cyclomatic number, MATCH Commun. Math. Comput. Chem. 53 (2005) 209-214.

[6] L. Feng, The Gutman index of unicyclic graphs, Discrete Math. Algorithms Appl. 4 (2012) 669-708. doi:10.1142/S1793830912500310

[7] L. Feng and W. Liu, The maximal Gutman index of bicyclic graphs, MATCH Commun. Math. Comput. Chem. 66 (2011) 699-708.

[8] I. Gutman, Distance of line graphs, Graph Theory Notes N. Y. 31 (1996) 49-52.

[9] I. Gutman, Selected properties of the Schultz molecular topological index, J. Chem. Inf. Comput. Sci. 34 (1994) 1087-1089.

doi:/10.1021/ci00021a009

[10] I. Gutman and L. Pavlović, More on distance of line graphs, Graph Theory Notes N. Y. 33 (1997) 14-18.

[11] M.H. Khalifeh, H. Yousefi-Azari, A.R. Ashrafi and S.G. Wagner, Some new results on distance-based graph invariants, European J. Combin. 30 (2009) 1149-1163. doi:10.1016/j.ejc.2008.09.019

[12] J.P. Mazorodze, S. Mukwembi and T. Vetrík, On the Gutman index and minimum degree, Discrete Appl. Math. 173 (2014) 77-82. doi:10.1016/j.dam.2014.04.004

[13] S. Mukwembi, On the upper bound of Gutman index of graphs, MATCH Commun. Math. Comput. Chem. 68 (2012) 343-348.

[14] M.J. Nadjafi-Arani, H. Khodashenas and A.R. Ashrafi, Relationship between edge Szeged and edge Wiener indices of graphs, Glas. Mat. Ser. III 47 (2012) 21-29. doi:10.3336/gm.47.1.02

[15] H. Whitney, Congruent graphs and the connectivity of graphs, Amer. J. Math. 54 (1932) 150-168. doi: $10.2307 / 2371086$

[16] H. Wiener, Structural determination of paraffin boiling points, J. Amer. Chem. Soc. 69 (1947) 17-20. doi:10.1021/ja01193a005 
Received 1 April 2015

Revised 30 December 2015

Accepted 30 December 2015 